\title{
TOXICITY STUDIES OF THE WATER EXTRACT FROM THE CALYCES OF HIBISCUS SABDARIFFA L. IN RATS
}

\section{Seewaboon Sireeratawong, ${ }^{1 *}$ Arunporn Itharat, ${ }^{2}$ Parirat Khonsung, ${ }^{3}$ Nirush Lertprasertsuke, ${ }^{4}$ Kanjana Jaijoy ${ }^{5}$}

${ }^{1}$ Division of Pharmacology, Department of Preclinical Science, Faculty of Medicine, Thammasat University, Pathum Thani 12120, Thailand., ${ }^{2}$ Department of Applied Thai Traditional Medicine, Faculty of Medicine, Thammasat University, Pathum Thani 12120, Thailand., ${ }^{3}$ Department of Pharmacology, Faculty of Medicine, Chiang Mai University, Chiang Mai 50200, Thailand., ${ }^{4}$ Department of Pathology, Faculty of Medicine, Chiang Mai University, Chiang Mai 50200, Thailand., ${ }^{5}$ cCormick Faculty of Nursing, Payap University, Chiang Mai 50000, Thailand.

*E-mail: seewaboon@gmail.com

\begin{abstract}
Acute and chronic toxicities of the water extract from calyces of Hibiscus sabdariffa were studied in male and female rats. After 14 days of a single oral administration of test substance $5,000 \mathrm{mg} / \mathrm{kg}$ body weight, measurement of the body and organ weights, necropsy and health monitoring were performed. No signs and differences of the weights or behaviour compared to the control rats were observed. The results indicated that the single oral administration of $H$. sabdariffa extract in the amount of $5,000 \mathrm{mg} / \mathrm{kg}$ body weight does not produce acute toxicity. The chronic toxicity was determined by oral feeding both male and female rats daily with the extract at the doses of 50, 100, and $200 \mathrm{mg} / \mathrm{kg}$ body weight for 270 days. The examinations of signs, animal behaviour and health monitoring showed no defects in the test groups compared to the control groups. Both test and control groups (day 270th) and satellite group (day 298th) were analysed by measuring their final body and organ weights, taking necropsy, and examining haematology, blood clinical chemistry, and microanatomy. Results showed no differences from the control groups. Overall, our study demonstrated that an oral administration of $H$. sabdariffa extract at the doses of 50,100 and $200 \mathrm{mg} / \mathrm{kg}$ body weight for 270 days does not cause chronic toxicity in rat.
\end{abstract}

Keywords: Hibiscus sabdariffa L., acute toxicity, chronic toxicity

\section{Introduction}

Hibiscus sabdariffa L. (family Malvaceae) is a plant found in many countries, and is commonly known as Roselle. The calyces have been used in folk medicines and claimed to be effective as antimicrobial, antiseptic, astringent, digestive, diuretics, hypertension, laxative, sedative, and stomachic (Perry, 1980), and used for treatment of pyrexia and liver disease (Mahadevan et al., 2009). The calyces contain a number of flavonoids gossypetin, hibiscetine and sabdaretine, ascorbic acid, mucilage, calcium citrate, etc. (Mahadevan et al., 2009).

Many studies have shown the pharmacological activities of $H$. sabdariffa. These include decreasing blood pressure in spontaneously hypertensive rats (Odigie et al., 2003; Onyenekwe et al., 1999; Adegunloye et al., 1996) as well as in patients with essential hypertension (Herrera-Arellano et al., 2004; Faraji and Tarkhani, 1999). H. sabdariffa extract was found to protect human erythrocytes against lipid peroxidation (Suboh et al., 2004). In addition, H. sabdariffa extract lowered serum lipids and showed an anti-atherosclerotic activity in cholesterol-fed rabbits and rats (Chen et al., 2003). The water and ethanolic extracts of $H$. sabdariffa have natural phenols content, antioxidant and antibacterial activity (Al-Hashimi, 2012).

The toxicity profiles of $H$. sabdariffa have been reported previously. In the acute toxicity test, no toxicity was observed within 7 days after oral administration at the high dose of $15 \mathrm{~g} / \mathrm{kg}$ ethanol and aqueous extracts of $H$. sabdariffa calyces in mice (Reanmongkol and Itharat, 2007). The prolonged usage at 15-dose level of the aqueous-methanolic extract of $H$. sabdariffa calyces at the dose of $250 \mathrm{mg} / \mathrm{kg}$ could cause liver injury in rats (Akindahunsi and Olaleye, 2003). The subchronic effect (12 weeks) of $H$. sabdariffa calyx aqueous extract at the doses of $1.15,2.30$, and $4.60 \mathrm{~g} / \mathrm{kg}$ induced testicular toxicity (Orisakwe et al., 2004). Moreover, a 90-day oral administration in albino rats of water and alcohol extracts of dried calyx of $H$. sabdariffa at a dose of $2,000 \mathrm{mg} / \mathrm{kg}$ caused the death of the animals, preceded by a severe loss in weight accompanied with diarrhoea (Fakeye et al, 2009). Although, H. sabdariffa is long used in traditional medicines, the chronic toxicity study of water extract has never been determined. This study was aimed at evaluating the safety of the water extract from the calyces of $H$. sabdariffa by single and long-term oral administration in rats.

\section{Materials and methods}

Plant material and preparation of the water extract from the calyces of $H$. sabdariffa

Red calyces of $H$. sabdariffa L. were collected at Khounmeet District in Songkhla Province, Thailand. The plant was identified by a direct comparison with herbarium specimens in the PSU Herbarium, Department of Biology, Faculty of 
Sciences, Prince of Songkla University. A voucher specimen No. SKP109 081001 of plant material has been deposited in the Faculty of Pharmaceutical Sciences, Prince of Songkla University, Thailand. The dried calyces of $H$. sabdariffa were extracted in hot water $\left(70^{\circ} \mathrm{C}\right)$ and then filtered. The filtrates were evaporated using vacuum drying $\left(40^{\circ} \mathrm{C}\right)$ under reduced pressure to give the aqueous extracts. This extract was stored at $4-5{ }^{\circ} \mathrm{C}$ after preparation.

\section{Animals}

Male and female Sprague-Dawley (SD) rats (190-220 g) were obtained from the National Laboratory Animal Center, Nakorn Pathom, Thailand. All animals were kept in the room, maintained under environmentally controlled conditions of $25 \pm 1^{\circ} \mathrm{C}$ and $12 \mathrm{~h}$ light- $12 \mathrm{~h}$ dark cycle. Food and water were available freely. All experimental protocols were approved by the Animal Ethics Committee of Faculty of Medicine, Thammasat University (No. 0006/2007).

\section{Acute toxicity test}

Forty SD rats, twenty males and twenty females, were used and divided into control and test groups. Before experiment, all rats were fasted overnight with free access to water. Ten males and ten females were administered orally with the water extract of $\mathrm{H}$. sabdariffa at the single dose of $5,000 \mathrm{mg} / \mathrm{kg}$. The control rats received distilled water. The sign of toxicity and death were observed over 2 weeks. During the experiment, food and water were available freely (Figure 1).

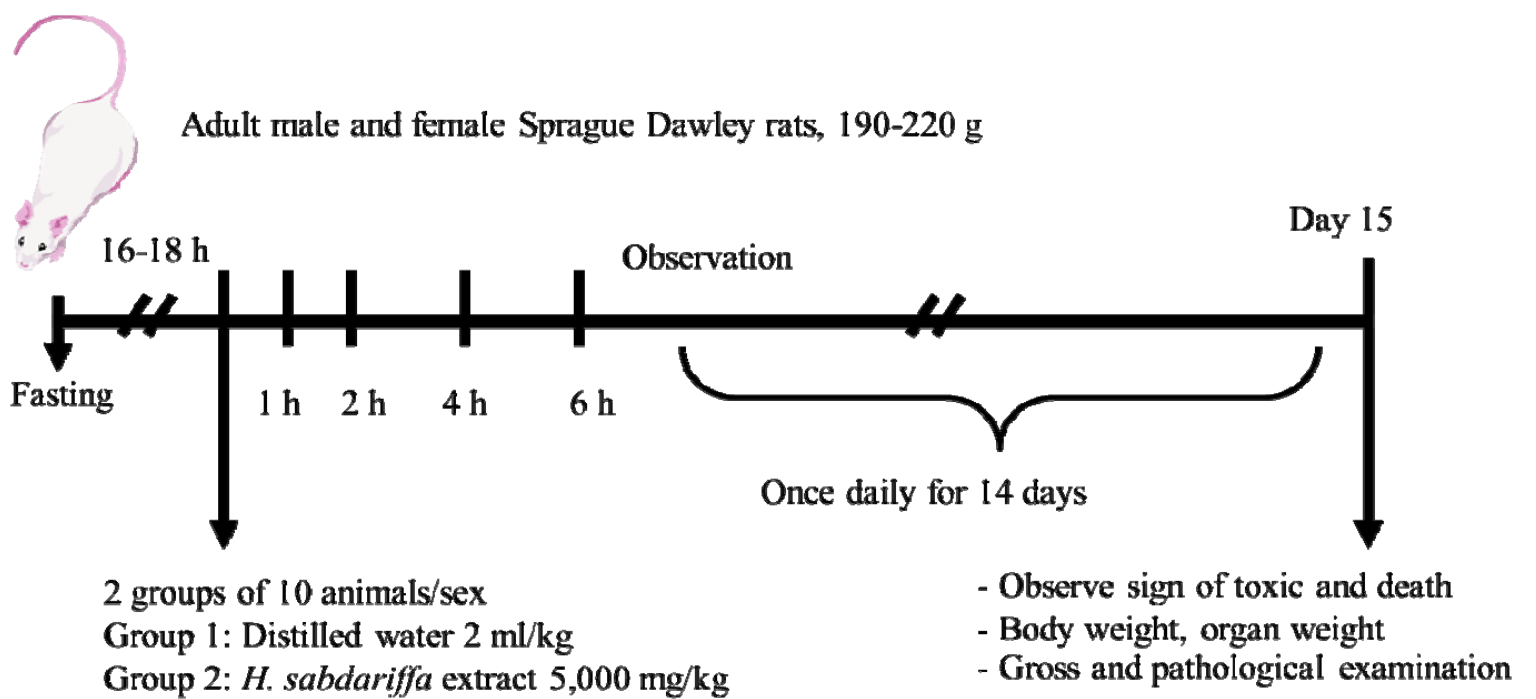

Figure 1 Scheme for Acute Toxicity Test of $H$. sabdariffa L. Extract

\section{Chronic toxicity test}

One hundred rats were divided into control and four test groups, 20 in each group (ten males and ten females). The animals were treated with distilled water and the extract at the doses of 50,100 , and $200 \mathrm{mg} / \mathrm{kg}$ daily for 270 days. The satellite group was administered orally with the extract at the dose of $200 \mathrm{mg} / \mathrm{kg}$ daily for 270 days and kept for another 28 days after the treatment in order to detect a delayed occurrence of toxic effect. Food and water were available freely during the experiment. The appearance of signs of toxicity, behavioural alterations, respiratory pattern, cardiovascular signs, motor activities, reflexes, change in skin and fur and mortality was observed and recorded. The body weight of rat was measured each week (Figure 2).

At the end of experiment, the rats were fasted 12 hours, and then sacrificed with the overdose of pentobarbital sodium $(100 \mathrm{mg} / \mathrm{kg}$, intraperitoneal injection). Their blood was collected from a common carotid artery with heparinised tubes. Red blood cell (RBC), haemoglobin (HB), haematocrit (HCT), mean corpuscular volume (MCV), mean corpuscular haemoglobin $(\mathrm{MCH})$, mean corpuscular haemoglobin concentration (MCHC), platelet (PLT), white blood cell (WBC), neutrophil (PMN), lymphocyte (LYMP), monocyte (MONO), eosinophill (EOS), and basophill (BASO) were detected by Sysmex K-1000 Fully Automated Haematology Analyser.

The serum was separated and we measured the levels of glucose (GLU), blood urea nitrogen (BUN), creatinine (CRE), total protein (TP), albumin (ALB), total bilirubin (T-BIL), direct bilirubin (D-BIL), total cholesterol (CHO), triglyceride (TG), serum glutamic-oxaloacetic transaminase (SGOT), serum glutamic-pyruvic transaminase (SGPT), and alkaline phosphatase (ALP), using the COBAS INTEGRA System.

The internal organs (brain, thymus, heart, lungs, livers, kidneys, spleen, adrenal glands, pancreas, small intestine, stomach and duodenum, muscle with sciatic nerve, thoracic spines, eyes, ovary, uterus, testis, and epididymis) were removed, weighted and observed for gross lesions. All tissues were preserved in $10 \%$ neutral buffered formaldehyde solution. Samples of the internal organs were dehydrated by serial ethanol solution and enclosed with paraffin. Micrometer sections $(5 \mu \mathrm{m}) \mathrm{cut}$ with microtome was stained with haematoxylin and eosin (H\&E) and examined under a light microscope. Photomicrographs of the samples were recorded. 


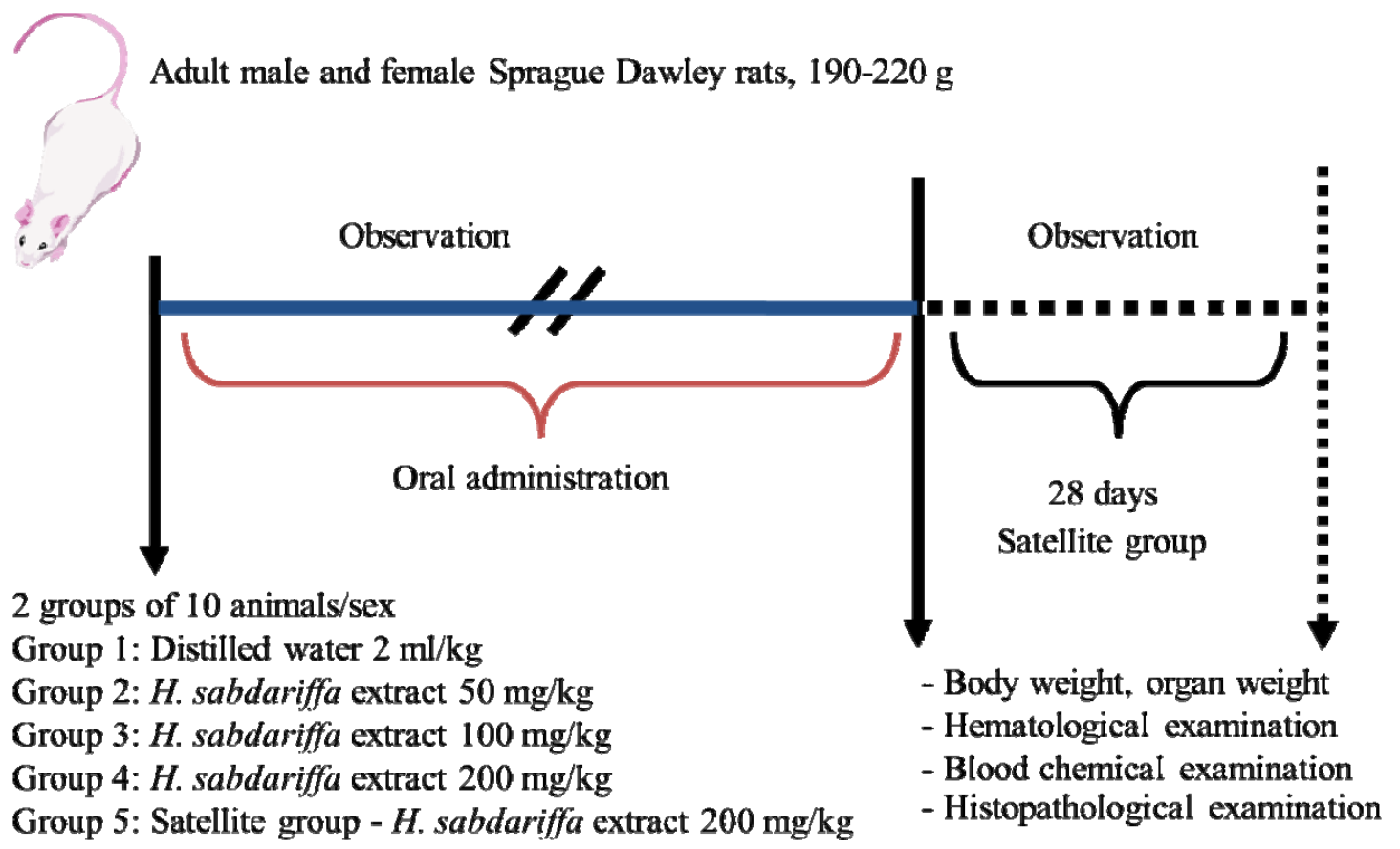

Figure 2 Scheme for Chronic Toxicity Test of H. sabdariffa L.

\section{Statistical analysis}

The values were expressed as mean \pm standard error of mean (S.E.M.). The statistics included one-way analysis of variance (ANOVA), Dunnett's test, and Student's $t$-test. $P<0.05$ was considered statistically significant.

\section{Results and discussion}

In this present study, an acute toxicity study of $H$. sabdariffa extract has been performed. A single administration of $H$. sabdariffa extract by the oral route up to a dose of $5000 \mathrm{mg} / \mathrm{kg}$ did not produce mortality, any signs of toxicity or changes in general behaviour or other physiological activities when compared with the control group. Moreover, the body weight and internal organ weight of treated rats were relatively similar to that of the control group. Additionally, gross and pathological examinations of the internal organs revealed no pathological abnormalities. According to the OECD guideline (2001), the result of acute toxicity test in this study indicated that $H$. sabdariffa extract has no acute oral toxicity.

While acute toxicity deals with the adverse effects of single doses, many chemical substances in the form of repeated doses do not produce immediate toxic effects. Delayed effects may occur due to accumulation of the chemical in tissues or to other mechanisms. Thus, it is important to identify any toxic potential of the substance by a chronic toxicity test. The use of a satellite group of test animals, given the highest dose and then observed after the ending of dosing, is to give additional information on the persistence or reversibility of effects (OECD, 1981). This study provides information on toxic effect, target organs, reversibility or a "no effect level".

The administration of $\mathrm{H}$. sabdariffa extract at a dose of 50,100 , and $200 \mathrm{mg} / \mathrm{kg}$ daily for 270 days caused neither any toxicity sign, abnormalities in behaviours nor death in rats. At day 270 , we detected the significantly decreased body weights of the female rats receiving extract at $50,100,200 \mathrm{mg} / \mathrm{kg}$, that of the male rats receiving $200 \mathrm{mg} / \mathrm{kg}$, as well as the male treated satellite group (Table 1). The weights of liver of the female group treated with 50 and $100 \mathrm{mg} / \mathrm{kg}$ were significantly less than those of the control group (Table 2). In the male groups treated with 50,100 and $200 \mathrm{mg} / \mathrm{kg}$ showed significant decrease in the kidney weight. Moreover, H. sabdariffa extract at a dose of $200 \mathrm{mg} / \mathrm{kg}$ significantly reduced the liver weight (Table 2). Nonetheless, these effects on the organ weight (liver and kidney) were normal due to organs' size and/or weight variation of animals. Therefore, the extract likely did not affect the animal organs. 
Table 1: Effect of H. sabdariffa extract on body weight of female and male rats

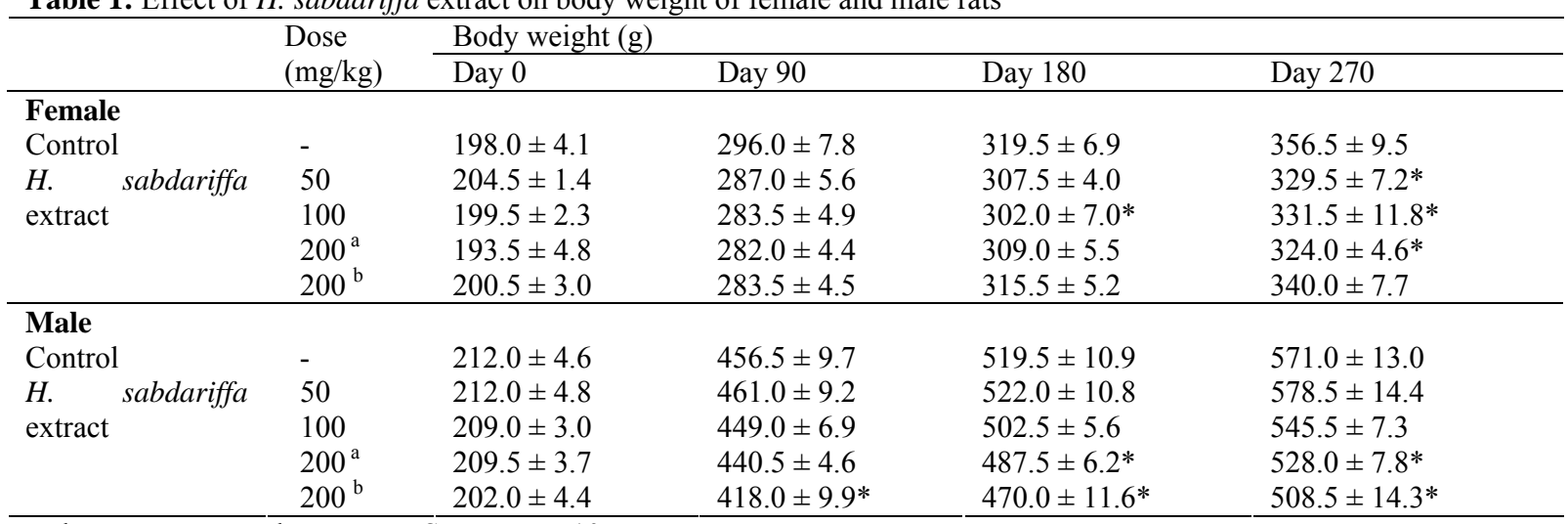

Values are expressed as mean \pm S.E.M., $\mathrm{n}=10$

*Significantly different from control, $p<0.05$

Table 2: Effect of $H$. sabdariffa extract on organ weights of rats

\begin{tabular}{|c|c|c|c|c|c|}
\hline & \multirow[b]{2}{*}{ Control } & \multicolumn{4}{|c|}{ H. sabdariffa extract } \\
\hline & & $50 \mathrm{mg} / \mathrm{kg}$ & $100 \mathrm{mg} / \mathrm{kg}$ & $200 \mathrm{mg} / \mathrm{kg}$ & Satellite \\
\hline \multicolumn{6}{|l|}{ Female } \\
\hline Lung & $1.4 \pm 0.0$ & $1.4 \pm 0.0$ & $1.5 \pm 0.0$ & $1.4 \pm 0.1$ & $1.6 \pm 0.1$ \\
\hline Heart & $1.1 \pm 0.0$ & $1.1 \pm 0.0$ & $1.1 \pm 0.0$ & $1.1 \pm 0.0$ & $1.19 \pm 0.0$ \\
\hline Liver & $8.9 \pm 0.4$ & $7.8 \pm 0.2^{*}$ & $8.1 \pm 0.3^{*}$ & $8.2 \pm 0.2$ & $8.8 \pm 0.2$ \\
\hline Pancreas & $1.2 \pm 0.0$ & $1.4 \pm 0.1$ & $1.2 \pm 0.1$ & $1.4 \pm 0.0$ & $1.4 \pm 0.1$ \\
\hline Spleen & $0.8 \pm 0.0$ & $0.8 \pm 0.0$ & $0.8 \pm 0.0$ & $0.8 \pm 0.0$ & $0.8 \pm 0.0$ \\
\hline Kidney & $1.2 \pm 0.0$ & $1.1 \pm 0.0$ & $1.1 \pm 0.0$ & $1.1 \pm 0.0$ & $1.2 \pm 0.0$ \\
\hline Ovary & $0.1 \pm 0.0$ & $0.1 \pm 0.0$ & $0.0 \pm 0.0$ & $0.1 \pm 0.0$ & $0.1 \pm 0.0$ \\
\hline Brain & $2.0 \pm 0.1$ & $1.9 \pm 0.0$ & $1.9 \pm 0.0$ & $1.9 \pm 0.0$ & $2.0 \pm 0.0$ \\
\hline \multicolumn{6}{|l|}{ Male } \\
\hline Lung & $2.0 \pm 0.1$ & $2.2 \pm 0.2$ & $1.8 \pm 0.0$ & $2.0 \pm 0.0$ & $1.9 \pm 0.1$ \\
\hline Heart & $1.6 \pm 0.0$ & $1.5 \pm 0.1$ & $1.6 \pm 0.0$ & $1.6 \pm 0.0$ & $1.5 \pm 0.0$ \\
\hline Liver & $14.8 \pm 0.3$ & $14.9 \pm 0.5$ & $13.9 \pm 0.3$ & $13.5 \pm 0.3^{*}$ & $14.5 \pm 0.4$ \\
\hline Pancreas & $1.6 \pm 0.1$ & $1.6 \pm 0.1$ & $1.7 \pm 0.1$ & $1.6 \pm 0.1$ & $1.5 \pm 0.1$ \\
\hline Spleen & $1.0 \pm 0.0$ & $1.0 \pm 0.0$ & $1.0 \pm 0.0$ & $1.0 \pm 0.0$ & $1.0 \pm 0.0$ \\
\hline Kidney & $1.8 \pm 0.0$ & $1.6 \pm 0.0^{*}$ & $1.6 \pm 0.0^{*}$ & $1.6 \pm 0.0^{*}$ & $1.7 \pm 0.0$ \\
\hline Testis & $2.0 \pm 0.0$ & $2.0 \pm 0.0$ & $2.0 \pm 0.0$ & $1.9 \pm 0.0$ & $2.0 \pm 0.0$ \\
\hline Epididymis & $0.9 \pm 0.0$ & $0.9 \pm 0.0$ & $0.8 \pm 0.0^{*}$ & $0.8 \pm 0.0$ & $0.9 \pm 0.0$ \\
\hline Brain & $2.0 \pm 0.0$ & $2.1 \pm 0.0$ & $2.0 \pm 0.0$ & $2.0 \pm 0.0$ & $2.0 \pm 0.0$ \\
\hline
\end{tabular}

Values are expressed as mean \pm S.E.M., $\mathrm{n}=10$

* Significantly different from control, $p<0.05$

Haematological examination revealed a significantly higher level of WBC in the treated group at the dose of $50 \mathrm{mg} / \mathrm{kg}$ and the satellite group. Significant decrease in the MCV of female and male rats, but increases in both the MCHC of female rats and the RBC of male rats were observed (Table 3). These parameters are useful as the RBC indices for differential diagnosis of anaemia (Voigt, 2000). However, these values detected are still within the normal range of SD rats (Inala et al., 2002).

Blood chemistry test is used to assess a wide range of conditions and the function of organs, especially the pancreas, liver and kidneys. In general, if the clinical blood chemistry values differ more or less than one fold from the normal values, the abnormality of these organs should be noted accordingly (Caisey and King, 1980; Sacher and McPherson, 2000). In our study, the clinical blood chemistry values indicated significant increases in the levels of plasma BUN and SGOT in the female rats treated with the extract at the dose of $50 \mathrm{mg} / \mathrm{kg}$. The level of SGPT was significantly increased in the rat treated with $200 \mathrm{mg} / \mathrm{kg}$. The amounts of TP and ALB were significantly decreased in the female satellite group (Table 4). The satellite group of male rats significantly showed increased level of GLU, but decreased levels of CHO and TP (Table 5). Although some clinical blood chemistry values were significantly changed in the extract-treated rats, these parameters are still within the normal range (Angkhasirisap et al., 2002). These results suggested that $H$. sabdariffa extract does not cause damages in the pancreas, liver or kidney, as confirmed by the pathological examination.

\section{Conclusion}

The water extract of $H$. sabdariffa calyces administered orally did not cause acute or chronic toxicities in both female and male rats. These results suggest the acute and long-term safety of $H$. sabdariffa. 
Table 3: Effect of $H$. sabdariffa extract on haematological values of rats

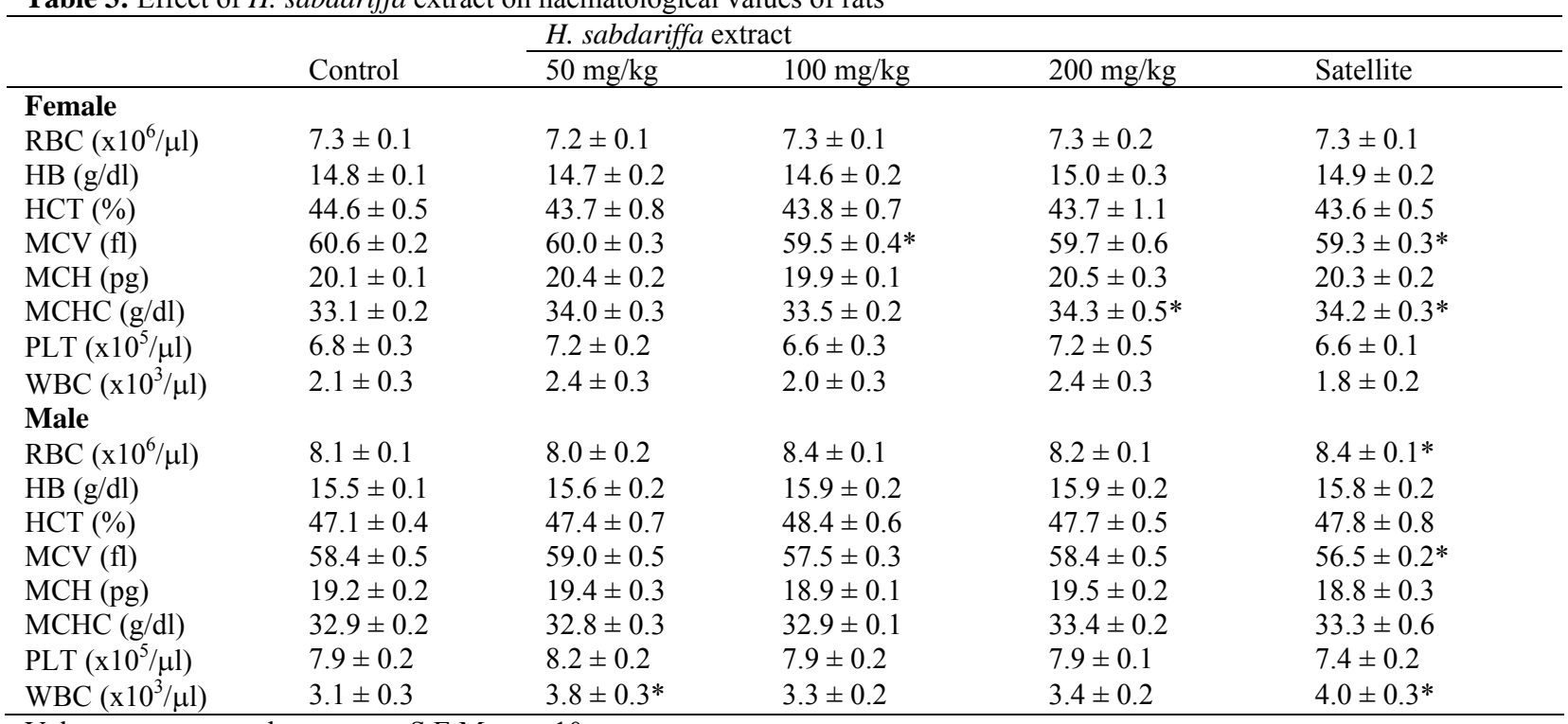

Values are expressed as mean \pm S.E.M., $\mathrm{n}=10$

*Significantly different from control, $p<0.05$

Table 4: Effect of $H$. sabdariffa extract on blood chemical values of female rats

\begin{tabular}{|c|c|c|c|c|c|}
\hline & \multirow[b]{2}{*}{ Control } & \multicolumn{4}{|c|}{ H. sabdariffa extract } \\
\hline & & $50 \mathrm{mg} / \mathrm{kg}$ & $100 \mathrm{mg} / \mathrm{kg}$ & $200 \mathrm{mg} / \mathrm{kg}$ & Satellite \\
\hline GLU (mg/dl) & $127.9 \pm 3.5$ & $131.6 \pm 4.0$ & $131.6 \pm 3.4$ & $128.3 \pm 4.3$ & $133.9 \pm 4.6$ \\
\hline BUN (mg/dl) & $21.5 \pm 0.9$ & $24.0 \pm 0.8^{*}$ & $23.4 \pm 0.7$ & $23.0 \pm 0.8$ & $21.6 \pm 0.6$ \\
\hline CRE (mg/dl) & $0.4 \pm 0.0$ & $0.5 \pm 0.0$ & $0.4 \pm 0.0$ & $0.4 \pm 0.0$ & $0.4 \pm 0.0$ \\
\hline $\mathrm{CHO}(\mathrm{mg} / \mathrm{dl})$ & $91.5 \pm 3.6$ & $87.2 \pm 4.2$ & $88.8 \pm 5.3$ & $89.6 \pm 3.2$ & $90.3 \pm 4.0$ \\
\hline TRI (mg/dl) & $59.5 \pm 4.1$ & $58.4 \pm 4.7$ & $64.6 \pm 7.7$ & $61.4 \pm 6.3$ & $58.1 \pm 2.7$ \\
\hline TP (g/dl) & $6.2 \pm 0.1$ & $6.1 \pm 0.1$ & $6.3 \pm 0.2$ & $6.0 \pm 0.2$ & $5.7 \pm 0.1 *$ \\
\hline $\operatorname{ALB}(\mathrm{g} / \mathrm{dl})$ & $4.3 \pm 0.1$ & $4.2 \pm 0.1$ & $4.2 \pm 0.1$ & $4.1 \pm 0.1$ & $3.9 \pm 0.1^{*}$ \\
\hline T-BIL (mg/dl) & $0.3 \pm 0.0$ & $0.2 \pm 0.0$ & $0.2 \pm 0.0$ & $0.2 \pm 0.0$ & $0.3 \pm 0.0$ \\
\hline D-BIL (mg/dl) & $0.0 \pm 0.0$ & $0.0 \pm 0.0$ & $0.0 \pm 0.0$ & $0.0 \pm 0.0$ & $0.0 \pm 0.0$ \\
\hline SGOT (U/l) & $172.2 \pm 10.5$ & $229.9 \pm 29.4^{*}$ & $156.6 \pm 11.9$ & $223.4 \pm 21.1$ & $184.2 \pm 10.9$ \\
\hline SGPT (U/1) & $51.5 \pm 5.3$ & $76.6 \pm 12.6$ & $51.3 \pm 3.9$ & $90.3 \pm 21.8 *$ & $53.7 \pm 4.9$ \\
\hline $\operatorname{ALP}(\mathrm{U} / 1)$ & $34.2 \pm 1.6$ & $31.6 \pm 1.8$ & $31.3 \pm 1.6$ & $30.0 \pm 2.2$ & $33.3 \pm 1.7$ \\
\hline
\end{tabular}

Values are expressed as mean \pm S.E.M., $\mathrm{n}=10$.

*Significantly different from control, $p<0.05$

Table 5: Effect of $H$. sabdariffa extract on blood chemical values of male rats

\begin{tabular}{|c|c|c|c|c|c|}
\hline & \multirow[b]{2}{*}{ Control } & \multicolumn{4}{|c|}{ H. sabdariffa extract } \\
\hline & & $50 \mathrm{mg} / \mathrm{kg}$ & $100 \mathrm{mg} / \mathrm{kg}$ & $200 \mathrm{mg} / \mathrm{kg}$ & Satellite \\
\hline GLU (mg/dl) & $135.2 \pm 2.5$ & $131.5 \pm 2.8$ & $138.3 \pm 3.4$ & $131.2 \pm 3.2$ & $146.0 \pm 3.3^{*}$ \\
\hline BUN (mg/dl) & $20.2 \pm 0.5$ & $21.9 \pm 1.5$ & $21.9 \pm 0.7$ & $21.4 \pm 1.0$ & $20.7 \pm 0.8$ \\
\hline CRE (mg/dl) & $0.4 \pm 0.0$ & $0.4 \pm 0.0$ & $0.4 \pm 0.0$ & $0.4 \pm 0.0$ & $0.4 \pm 0.0$ \\
\hline $\mathrm{CHO}(\mathrm{mg} / \mathrm{dl})$ & $114.4 \pm 3.5$ & $117.0 \pm 3.4$ & $116.5 \pm 3.7$ & $113.3 \pm 3.2$ & $101.2 \pm 1.9^{*}$ \\
\hline TRI (mg/dl) & $50.2 \pm 3.9$ & $58.9 \pm 2.8$ & $57.7 \pm 3.3$ & $54.1 \pm 4.2$ & $47.5 \pm 2.5$ \\
\hline $\mathrm{TP}(\mathrm{g} / \mathrm{dl})$ & $6.0 \pm 0.1$ & $6.2 \pm 0.1$ & $6.2 \pm 0.0$ & $6.1 \pm 0.1$ & $5.7 \pm 0.1^{*}$ \\
\hline $\operatorname{ALB}(\mathrm{g} / \mathrm{dl})$ & $3.7 \pm 0.1$ & $3.7 \pm 0.1$ & $3.7 \pm 0.0$ & $3.7 \pm 0.1$ & $3.6 \pm 0.1$ \\
\hline T-BIL (mg/dl) & $0.2 \pm 0.0$ & $0.2 \pm 0.0$ & $0.2 \pm 0.0$ & $0.2 \pm 0.0$ & $0.2 \pm 0.0$ \\
\hline D-BIL (mg/dl) & $0.0 \pm 0.0$ & $0.0 \pm 0.0$ & $0.0 \pm 0.0$ & $0.0 \pm 0.0$ & $0.0 \pm 0.0$ \\
\hline SGOT (U/1) & $174.8 \pm 14.6$ & $191.9 \pm 18.7$ & $183.2 \pm 13.4$ & $206.0 \pm 27.2$ & $157.2 \pm 27.0$ \\
\hline SGPT (U/1) & $56.6 \pm 4.1$ & $50.4 \pm 2.6$ & $57.9 \pm 3.7$ & $62.8 \pm 9.1$ & $69.1 \pm 15.6$ \\
\hline $\mathrm{ALP}(\mathrm{U} / \mathrm{l})$ & $49.4 \pm 2.3$ & $55.0 \pm 2.3$ & $55.8 \pm 2.2$ & $55.1 \pm 1.7$ & $50.5 \pm 3.7$ \\
\hline
\end{tabular}

Values are expressed as mean \pm S.E.M., $\mathrm{n}=10$

*Significantly different from control, $p<0.05$ 


\section{Acknowledgement}

The authors are grateful to the National Research Council of Thailand for financial support.

\section{References}

1. Adegunloye, B.J., Omoniyi, J.O., Owolabi, O.A., Ajagbonna, O.P., Sofola, O.A. and Coker, H.A. (1996). Mechanisms of the blood pressure lowering effect of the calyx extract of Hibiscus sabdariffa in rats. Afr. J. Med. Sci. 25: 235 - 238.

2. Akindahunsi, A.A. and Olaleye, M.T. (2003). Toxicological investigation of aqueous-methanolic extract of the calyces of Hibiscus sabdariffa L. J. Ethnopharmacol. 89: 161 - 164.

3. Al-Hashimi, A.G. (2012). Antioxidant and antibacterial activities of Hibiscus sabdariffa L. extracts Afr J Food Sci. 6(21): $506-511$.

4. Angkhasirisap, W., Inala, P., Sirimontaporn, A., Inpunkaew, R., Rungrojejinda, K., Kengkoom, K., Ratanasak, W., and Buripadi Lawson, D. (2002). Blood chemistry profiles of outbred Sprague-Dawley rat in the Facility of National Laboratory Animal Centre. $28^{\text {th }}$ Congress on Science and Technology of Thailand.

5. Caisey, J.D. and King D.J. (1980). Clinical chemical values for some common laboratory animals. Clin. Chem. $26: 1877$ 1879.

6. Chen, C.C., Hsu, J.D., Wang, S.F., Chiang, H.C., Yang, M.Y., Kao, E.S., Ho, Y.C. and Wang, C.J. (2003). Hibiscus sabdariffa extract inhibits the development of atherosclerosis in cholesterolfed rabbits. J. Agri. Food Chem. $51: 5472$ - 5477.

7. Fakeye, T.O., Pal, A, Bawankule, D.U., Yadav, N.P. and Khanuja, S.P. (2009). Toxic effects of oral administration of extracts of dried calyx of Hibiscus sabdariffa Linn. (Malvaceae). Phytother. Res. 23(3): 412 - 416.

8. Faraji, M.H. and Tarkhani, A.H.H. (1999). The effect of sour tea (Hibiscus sabdariffa) on essential hypertension. J. Ethnopharmacol. 65: $231-236$.

9. Herrera-Arellano, A., Flores-Romero, S., Chavez-Soto, M.A. and Tortoriello, J. (2004). Effectiveness and tolerability of a standardized extract from Hibiscus sabdariffa in patients with mild to moderate hypertension: a controlled and randomized clinical trial. Phytomedicine. 11: 375 - 382.

10. Inala, P., Sirimontaporn, A., Inpunkaew, R., Rungrojejinda, K., Kengkoom, K., Ratanasak, W. and Buripakdi Lawson, D. (2002). Hematological analysis of outbred Sprague-Dawley rat in The Facility of National Laboratory Animal Centre. $28^{\text {th }}$ Congress on Science and Technology of Thailand.

11. Mahadevan, N., Shivali, A. and Kamboj, P. (2009). Hibiscus sabdariffa Linn.-An overview. Natural Product Radiance. 8(1): $77-83$.

12. Odigie, I.P., Ettarh, R.R. and Adigun, S.A. (2003). Chronic administration of aqueous extract of Hibiscus sabdariffa attenuates hypertension and reverses cardiac hypertrophy in 2K-1C hypertensive rats. J. Ethnopharmacol. 86: 181 - 185.

13. Onyenekwe, P.C., Ajani, E.O., Ameh, D.A. and Gamaniel, K.S. (1999). Antihypertensive effect of roselle (Hibiscus sabdariffa) calyx infusion in spontaneously hypertensive rats and a comparison of its toxicity with that in Wistar rats. Cell Biochem. Funct. 17: 199 - 206.

14. Organization of Economic Co-operation and Development. (2001). The OECD guideline for testing of chemical: 420 Acute Oral Toxicity. France.

15. Organization of Economic Co-operation and Development. (1981). The OECD guideline for testing of chemical: 452 Chronic Toxicity Study. France.

16. Orisakwe, O.E., Husaini, D.C. and Afonne, O.J. (2004). Testicular effects of sub-chronic administration of Hibiscus sabdariffa calyx aqueous extract in rats. Reprod. Toxicol. 18: 295 - 298.

17. Perry, J.M. (1980). Medicinal plants of East and Southeast Asia: attributed properties and uses. MIT Press, Cambridge, MA, pp $334-360$.

18. Reanmongkol, W. and Itharat, A. (2007). Antipyretic activity of the extracts of Hibiscus sabdariffa calyces L. in experimental animals. Songklanakarin J. Sci. Technol. 29(Suppl. 1): 29 - 38.

19. Sacher, R.A. and McPherson, R.A. (2000). Test of liver function. In: Sacher RA, McPherson RA, Campos JM, Widmann FK, eds. Widmann's clinical interpretation of laboratory test, $11^{\text {th }}$ ed. F.A. Davis Company, U.S.A., pp $562-599$.

20. Suboh, S.M., Bilto, Y.Y. and Aburjai, T.A. (2004). Protective effects of selected medicinal plants against protein degradation, lipid peroxidation and deformability loss of oxidative stressed human erythrocytes. Phytother. Res. 18: 280 284.

21. Voigt, G.L. (2000). Anemias and Polychythenias. In Hematology Techniques and Concepts for Veterinary Technicians. Iowa State University Press, U.S.A., pp 95 - 101. 